\title{
THE ROLE OF HEALTH LITERACY IN PREDICTING PATIENT SATISFACTION WITH HEALTH CARE
}

\author{
Vineta Silkane \\ Vidzeme University of Applied Sciences, Latvia \\ Agnese Davidsone \\ Vidzeme University of Applied Sciences, Latvia \\ Linda Veliverronena \\ Vidzeme University of Applied Sciences, Latvia
}

\begin{abstract}
Patient satisfaction has become one of the central indicators to measure quality of provision of health care services. However, it has been made clear in previous literature that the effectiveness and efficiency of the health care services is not directly proportional to the satisfaction level, because an array of patient's personal, psychological, and cognitive factors such as beliefs, expectations, knowledge and others may come into play. In this current article, we report on a study aiming to examine the role of health literacy in predicting patient satisfaction with health care in Latvia. In summer-autumn 2017, data were collected from a random sample of 451 participants (44\% male) in age from 18 to 81 years. The participants filled-in the questionnaire consisting of: Patient Satisfaction Questionnaire (PSQ-III, Ware, Snyder, \& Wright, 1976) and European Health Literacy Survey Questionnaire (HLS-EU-Q, HLS-EU Consortium, 2012). We measured four out of the seven aspects of PSQ, namely, general satisfaction, technical quality, interpersonal aspects, and communication. HLS-EU-Q contains three subscales: health care, disease prevention, and health promotion. Study results confirm that one of the health literacy aspects - health care - was the most important predictor of all patient satisfaction aspects, while health promotion predicted technical quality.
\end{abstract}

Keywords: patient satisfaction, health literacy.

\section{Introduction}

Latvia traditionally has given low priority to health care system, and consequently it suffers from poor public financing in long term. In fact, expenditure for the health care system in Latvia is almost twice as low as average public spending in OECD countries, also health status of Latvians lags behind, compared to other OECD countries (OECD, 2017). According to Health Consumer Powerhouse`s Euro Health consumer Index, in 2008 Latvian health care was ranked as the most unfriendly health care system in Europe. Despite improvements, eight years later, in 2016, it was still ranked among at least patientcentred health care systems. As the comparative study demonstrated, patients 
must cover themselves a substantial part of the costs across all health services (OECD, 2017). Under these conditions, patient health literacy becomes increasingly significant, as it is associated with maintenance of health, wellbeing, prevention of illnesses, and ability to seek, understand and utilise health care information (Sørensen et al., 2012), which is highly needed and essential to navigate individuals through Latvian health care system.

Latvian government has introduced a set of legal norms aimed to reform our health care system and urge medical care institutions to show greater interest into patient satisfaction with the provision of health care services. Medical care institutions in Latvia establish patient satisfaction measurement systems gradually; however, main attention till now has been focused to the systemic aspects that affect patient satisfaction (Ministry of Health of the Republic of Latvia, 2017). Unfortunately, such approach where individual factors are largely neglected, does not lead to full understanding of the situation. Therefore, based on the argument that patient's awareness, and knowledge of health-related issues influence the patient satisfaction, this study focuses on a crucial individual aspect of patients - health literacy. The aim of the current study is to explore the role of health literacy in predicting patient satisfaction with health care in Latvia. The study strives to promote the debate about the importance of health literacy in shaping patient satisfaction. Research data were collected during a survey with a random sample consisting of 451 participants.

Number of previous studies have focused on the relationship between patient satisfaction and health literacy (e.g. Shea et al., 2007; Kaphingst et al., 2014; Altin \& Stock, 2015; Komenaka et al., 2014, 2016; Macleod et al., 2017; Verkissen et al., 2014); yet, health literacy only recently has gained attention of researchers in Latvia and is not enough discussed topic in public space. Few isolated studies focus on health literacy in Latvia such as Policy recommendations of health literacy by The Standing Committee of European doctors and Latvian Human Development report 2015/2016 on Mastery of Life and Information Literacy contained the chapter of health literacy (Rasnača et al., 2017)

During last few decades, medico-social services, patient care relations and patient guidance counselling have been introduced in health care institutions (Von Wagner et al., 2009). The overall trend in health care to treat patients as clients (Priporas et al., 2008; Gourley \& Duncan, 1998) urges hospitals to measure not only quality of delivered health care services but also patient satisfaction. Consequently patient satisfaction has become one of the critical indicators for measuring the health care quality. It contradicts traditional approach when quality evaluation was based on provided medical services (Von Wagner et al., 2009). Overall patient satisfaction is multidimensional, hard-to-define and measure concept, depending on various socio-demographic characteristics of patients (Shea et al., 2007). Availability of services, reliability, continuity, reliability, 
efficiency, treatment results, service provider`s communications skills are cited as factors affecting patient assessment of received health care. (Naidu, 2009: 367368) However, effectiveness and efficiency of the health care services is not directly proportional to the satisfaction level, because an array of patient's personal, psychological, and cognitive factors such as beliefs, knowledge and others may come into play. Previous studies have generated lists of influences, e.g. Naidu (2009: 371-372) indicates that patients expectations are related to the culture and specifics of health care system. Priporas et al. (2008) states patients do not have clear expectations in clinical setting, and their` criteria for satisfaction measurement also depends on severity of illness, on the stage of treatment as at some stages patients are unable to draw conclusions. (Priporas et al., 2008: 324325). DiMatteo et al. (2014) cites low health literacy as one of the major impediments to accurate assessment of patient's adherence.

Patient activation enhance patient satisfaction and the shift in the patientphysician relationship suggests patients should actively participate in their health care, through engaging in shared decision making, asking questions, and other services (Shea et al., 2007); however, there are pre-conditions for the person to be able actively engaged in the process of health maintenance or disease treatment. Previous studies cite list of factors having negative impact to patient activity such as limited health literacy, low level of confidence, emotions and individual characteristics of patients. From the perspective of service providers, the barriers for patient involvement are time pressure, limited communication skills, and attitude (Laidsaar-Powell et al., 2014: 99-100).

The complexity of modern health care system settings emphasizes the increasing need to patient health literacy (Berkman et al., 2014). Health literacy, alike patient satisfaction, is a widely applied concept with various definitions; however, all definitions have in common "the focus on individual skills to obtain, process and understand health information and services necessary to make appropriate health decisions" (Sørensen et al., 2012). Health information seeking has important role in the process of patient empowerment because it is considered "purposeful and goal oriented activity rather the result of passive exposure to information" (Graffigna et al., 2017: 1919). Patient health literacy and specifically the ability to seek, understand and use of information is critical determinant defining if the person is able to participate in the health care process (Jordan et al., 2010: 36).

Recently, studies move beyond individual focus and consider health literacy "as an interaction between the demands of health systems and the skills of individuals" (Sørensen et al., 2012). Broader understanding of health literacy emphasizes the significance of health context and circumstances that may be outside of individuals' control. (Jordan et al., 2013) The framework of Health literacy management scale extends the concept of health literacy by including 
number of domains such as proactive health related behaviour, being able to ask for social support, capacity to communicate to health care professionals, socioeconomic considerations defining to what extent individual can afford health care (Jordan et al., 2013: 233). Komenaka et al. (2014) has found limited health literacy is a barrier for patient-physician communication. Other studies indicate patients with inadequate health literacy are at risk not being able to proceed information that they are provided by the physicians (Verkissen et al., 2014). In summary: health literacy has become central in the context of empowerment of the patient and patient - physician communication in the increasingly complex health care system.

The association between patient health literacy and health outcomes is well established (Von Wagner et al., 2009), as low health literacy has been associated with wide range of health related outcomes, including poorer overall health status and higher risk of hospitalization (McCray, 2005). At the same time, it is unlikely that health literacy has direct effects on most health outcomes as its impact is mediated by external factors attributed to health care system or health care provider (Von Wagner et al., 2014).

Previous studies suggest that the level of patient health literacy can predict overall patient satisfaction with provided health care (Macleod et al., 2017). Findings of the study by Shea et al. (2007) confirm that health literacy although weakly but yet consistently predicts primary care patient dissatisfaction. Macleod et al. (2017) claims individuals with insufficient health literacy express lower satisfaction with physicians and overall health care delivery. Findings allow to identify characteristics shared by adults with insufficient health literacy, - more likely they are to be older, male, minorities, have lower income and education and they generally are in poorer physical and mental condition (Macleod et al., 2017: 335). Altin and Stock (2015) have explored the patient satisfaction with primary care services in the context of individual`s health literacy, patient centred communication and shared decision making. Their study demonstrates that patients with limited health literacy skills and experiencing poor patient-centred communication are likely to be less satisfied with provided care (Altin \& Stock, 2015).

\section{Method}

Participants. In the study 451 adults (44\% male) in age from 18 to 81 years $(M=41.28, S D=13.31)$ participated. The duration of formal education of respondents was from 4 to 33 years $(M=15.53, S D=3.05)$.

Instruments. The participants filled-in the questionnaire consisting of: Patient Satisfaction Questionnaire (PSQ-III, Ware, Snyder, \& Wright, 1976) and European Health Literacy Survey Questionnaire (HLS-EU-Q, HLS-EU 
Consortium, 2012), as well as responded a number of questions about the frequency of illnesses that have required or had not required medical assistance, and respondents' demographic information such as age, gender, and length of formal education.

Patient Satisfaction Questionnaire (PSQ-III, Ware, Snyder, \& Wright, 1976) was adapted in Latvian as part of this study. Patient Satisfaction Questionnaire consists of seven sub-scales, of which four sub-scales were used in this study: General Satisfaction (e.g. "very satisfied with care”), Technical Quality (e.g. "doctors are competent, well-trained"), Interpersonal Aspects (e.g. "very friendly and courteous") and Communication (e.g. "explain the reason for tests"). The three sub-scales Time Spent with Doctor, Financial Aspects, and Access / Availability were not used in this study for following reasons: 1) Time Spent with Doctor includes only two items, 2) Financial Aspects and Access / Availability consist of items related to health system problems in Latvia and the interest of researchers was more focused on the personal aspects of patient satisfaction. 28 items were used in the instrument, and the five-point scale was used for answers: 1 - strongly agree, 2 - agree, 3 - uncertain, 4 - disagree, 5 - strongly agree. In previous studies Cronbach's alpha varies from .82 to .88 (Hay, Davies, \& Ware, 1987), in this study the variation is from .77 to .82.

Health Literacy Survey Questionnaire (HLS-EU-Q, HLS-EU Consortium, 2012) consists of three sub-scales: Health care (16 items), Disease prevention (15 items), and Health promotion (16 items) about ability to access health related information, ability to understand health related information, ability to interpret and evaluate health related information, and ability to make informed decisions on medical and health issues (Sorensen et al., 2012). The five-point scale was used for answers: 1 - very difficult, 2 - fairly difficult, 3 - fairly easy, 4 - very easy, 5 - don't know. In this study Cronbach's alpha varies from .89 to .90. In the survey carried out by European Health Literacy Project the variance was from .91 to .92 (HLS-EU Consortium, 2012).

Procedure. In summer-autumn 2017 data were collected using Google forms. Respondents were invited to participate in the study using social networking sites and e-mail. The respondents were introduced to the topic of the study and informed about the anonymity. Participation in the study was voluntary.

Data analysis. Data was analysed using IBM SPSS Statistics 22. Correlation analysis and hierarchical regression analysis was performed. The results were considered at the level of significance $p<.05, p<.01$ and $p<.001$.

\section{Results}

Hierarchical regression analysis was performed to determine the role of health literacy in predicting patient satisfaction. The assumptions of linearity, 
normally distributed errors, and uncorrelated errors were checked and met. Means, standard deviations and correlations are presented in Table 1.

Regression analysis was performed on four aspects of patient satisfaction general satisfaction, technical quality, interpersonal aspects, and communication. The following variables were included in the first stage of hierarchical regression analysis: gender, age, education, frequency of illness that does not require medical assistance, and frequency of illness requiring medical assistance.

Table 1 Descriptive statistics, Cronbach alpha and correlations of patient satisfaction and health literacy subscales

\begin{tabular}{lccccccccc}
\hline & $\alpha$ & $M$ & $S D$ & 2. & 3. & 4. & 5. & 6. & 7. \\
\hline 1. General Satisfaction & .80 & 2.43 & .62 & .67 & .68 & .61 & .32 & .21 & .27 \\
2. Technical Quality & .82 & 3.00 & .56 & & .76 & .76 & .40 & .27 & .33 \\
3. Interpersonal & .81 & 2.93 & .63 & & & .77 & .40 & .28 & .32 \\
Aspects & & & & & & & & & \\
4. Communication & .75 & 3.22 & .67 & & & & .41 & .26 & .28 \\
5. Health Care & .89 & 2.93 & .42 & & & & & .68 & .55 \\
6. Disease prevention & .89 & 2.90 & .48 & & & & & & .69 \\
7. Health promotion & .90 & 2.80 & .48 & & & & & & \\
\hline Note All the correlation coefficients in the table are statistically significant $p<.01$ & &
\end{tabular}

Note. All the correlation coefficients in the table are statistically significant $p<.01$

In case of general satisfaction all controlling variables explained $9 \%$ of the variance $(F(5,435)=8.90, p<.001)$, gender $(\beta=.12, p<.05)$, age $(\beta=-.13$, $p<.01)$ and frequency of illness that does not require medical assistance $(\beta=-.26, p<.001)$ were significant predictors. When all health literacy aspects were added, they improved the prediction and $17 \%$ of the variance was explained $(F(8,432)=11.48, p<.001)$. Individuals who were less likely to suffer from illnesses that did not require medical assistance, as well as men, were slightly more satisfied with medical care. Health care as one of health literacy domains $(\beta=.30, p<.001)$ was significant predictor of patient general satisfaction. In case of technical quality, controlling variables explained only $3 \%$ of the variance $(F(5,434)=2.58, p=.026)$, frequency of illness that does not require medical assistance $(\beta=-.12, p<.05)$ was predictor of technical quality. In case of interpersonal aspects, controlling variables explained $4 \%$ of the variance $(F(5,436)=3.66, p=.003)$ and education turned out to be the predictor of satisfaction with interpersonal aspects $(\beta=.10, p<.05)$. In case of communication, controlling variables were explained only at $4 \%$ of the variance $(F(5,435)=3.35, p=.006)$. When all health literacy domains were added, they improved the prediction and $18 \%$ of the variance was explained in case of technical quality $(F(8,431)=11.83, p<.001), 19 \%$ - in case of interpersonal aspects $(F(8,433)=13.04, p<.001)$, and $19 \%$ - in case of communication $(F(8,432)=12.28, p<.001)$. In all cases health care was significant predictor of 
patient satisfaction (general satisfaction $\beta=.30, p<.001$, technical quality $\beta=.38, p<.001$, interpersonal aspects $\beta=.37, p<.001$, communication $\beta=.40$, $p<.001)$. All standardized coefficients and $\mathrm{R}$ square change are presented in Table 2.

Table 2 Summary of hierarchical regression analysis for variables predicting patient satisfaction

\begin{tabular}{|c|c|c|c|c|c|c|c|c|}
\hline \multirow[b]{3}{*}{$\begin{array}{l}\text { Independent } \\
\text { variables }\end{array}$} & \multicolumn{8}{|c|}{ Dependent variables: Patient satisfaction } \\
\hline & \multicolumn{2}{|c|}{$\begin{array}{c}\text { General } \\
\text { Satisfaction }\end{array}$} & \multicolumn{2}{|c|}{$\begin{array}{c}\text { Technical } \\
\text { Quality }\end{array}$} & \multicolumn{2}{|c|}{$\begin{array}{c}\text { Interpersonal } \\
\text { Aspects }\end{array}$} & \multicolumn{2}{|c|}{ Communication } \\
\hline & $\beta$ & $\Delta R^{2}$ & $\beta$ & $\Delta R^{2}$ & $\beta$ & $\Delta R^{2}$ & $\beta$ & $\Delta R^{2}$ \\
\hline Step 1 & & .09 & & .03 & & .04 & & .04 \\
\hline Gender & $.12 *$ & & .04 & & .08 & & .05 & \\
\hline Age & $-.13^{* *}$ & & -.08 & & -.06 & & -.06 & \\
\hline Education & .01 & & .09 & & $.10 *$ & & .07 & \\
\hline $\begin{array}{l}\text { Frequency of } \\
\text { illness }^{\text {a }}\end{array}$ & $-.26^{* * *}$ & & $-.12 *$ & & -.11 & & -.07 & \\
\hline $\begin{array}{l}\text { Frequency of } \\
\text { illness } b\end{array}$ & .07 & & -.001 & & -.05 & & -.11 & \\
\hline Step 2 & & .08 & & .15 & & .15 & & .15 \\
\hline Gender & $.12 *$ & & .04 & & .09 & & .06 & \\
\hline Age & -.08 & & -.01 & & .004 & & .004 & \\
\hline Education & -.03 & & .04 & & .04 & & .03 & \\
\hline $\begin{array}{l}\text { Frequency of } \\
\text { illness }^{a}\end{array}$ & $-.23 * * *$ & & -.07 & & -.06 & & -.03 & \\
\hline $\begin{array}{l}\text { Frequency of } \\
\text { illness } \mathrm{b}\end{array}$ & .09 & & .02 & & -.03 & & -.08 & \\
\hline Health Care & $.30 * * *$ & & $.38^{* * *}$ & & $.37 * * *$ & & $.40 * * *$ & \\
\hline Disease prevention & -.11 & & -.13 & & -.08 & & -.12 & \\
\hline Health promotion & .11 & & $.19 *$ & & .14 & & .11 & \\
\hline$R^{2}$ & . & .17 & & .18 & & .19 & & .19 \\
\hline
\end{tabular}

\section{Discussion and conclusions}

This study focused on an under-researched area in the field of patient satisfaction, namely, the role of health literacy in predicting patient satisfaction with health care services in Latvia. Arguing that along with the systemic aspects, the patient individual aspects such as health literacy should be given an equally significant role, we carried out our survey with a patient satisfaction measurement instrument that specifically focused on communication, interpersonal aspects, 
technical quality and general satisfaction of patients. Further, based on our results, we discuss the role of health literacy in predicting these four aspects of patient satisfaction. We distinguish between three domains of health literacy, based on Sorensen et al. (2012): health care, disease prevention, and health promotion that all shape and entail patients' knowledge, competences and, motivation to access, understand, evaluate and apply health-related information and make informed decisions, and take action.

In our study the general satisfaction was mainly predicted by frequency of illness that does not require medical assistance, and the gender played a role too, male respondents turned out to be slightly more generally satisfied with the health care services than females. Based on this we can conclude that patients who have less experience with health care services, are more satisfied. Individuals having better understanding of health related information and ability to interpret and evaluate information, are more satisfied with the competencies and medical experience of physician, which might suggest they more appreciate health care service providers.

In spite the fact that previous studies suggest that the level of patient health literacy, especially in older population, can predict overall patient satisfaction (Macleod et al., 2017), our findings show that, measured separately, each domain of health literacy has only a week relationship with patient satisfaction. However, when all health literacy domains were added to regression, they improved the prediction of patient overall satisfaction to 17-19\%. Our findings thus are in line with the results of previous studies (e.g., Shea et al., 2007) pointing out that health literacy does not alone predict general patient satisfaction. Our findings suggest that one of the health literacy domains - health care - turned out to be the strongest predictor of patient satisfaction in all cases, while patient's satisfaction with the technical quality of the health care services was predicted by the domain of health care, and additionally by the domain of health promotion. The least predictor among all three was the domain of disease prevention.

Three conclusions can be derived from these findings: first, the patient's ability to access, understand and evaluate relevance of various risk factors elements that are associated with disease prevention and are in line with the concept of active and empowered individual (Shea et al., 2007) who interacts with health care professionals - should be examined more closely. It is due to the fact that in our study, the disease prevention domain showed no significance in predicting patient satisfaction, while previous studies (e.g., Jordan et al., 2013) emphasize the crucial role of proactive health related behaviour of patients. Second conclusion is that the domain of health promotion of health literacy plays an important role regarding satisfaction with interpersonal aspects and communication, which means that patients who are more informed and knowledgeable on the domain of health promotion, are more able to understand 
the received information and as a result more satisfied with the health care services. Attention therefore should be paid towards educating patients and explaining them the diagnosis and treatment recommendations. Medical personnel might need specific training to recognise low health literacy and develop strategies that enhance the communication between patient and doctor to make sure that patients understand what they have been told. This might lead to higher level of adherence, as the previous research show (Komenaka et al., 2014; Verkissen et al., 2014). Finally, health literacy should not be overlooked as a sole predictor of patient satisfaction. Instead, future studies should take a complex and multidimensional approach and combine patients individual aspects such as health literacy with the ones associated with the systemic influences.

\section{References}

Al-Abri, R., \& Al-Balushi, A. (2014). Patient satisfaction survey as a tool towards quality improvement. Oman Medical Journal, 29 (1), 3-7.

Altin, S. V., \& Stock, S. (2015). Impact of health literacy, accessibility and coordination of care on patient's satisfaction with primary care in Germany. BMC Health Service Research, 16:450.

Berkman, N. D., Davis, T. C., \& McCormack, L. (2010). Health Literacy: What Is It?, Journal of Health Communication, 15 (S2), 9-19.

DiMatteo, R., M., Miller, T. A., \& Martin, L. R. (2014). The importance of effective Measurement for Fostering Changes. In Martin, L. R., DiMatteo, M. R. (Eds.) The Oxford Handbook of Health Communication, Behavior Change, and Treatment Adherence (pp 370-386). Oxford, New York: Oxford University Press.

Gourley, G. A., \& Duncan, D. V. (1998). Patient satisfaction and quality of life: Humanistic outcomes. Journal of Managed Care, 4 (5), 746-752.

Graffigna, G., Barello, S., Bonanomi, A., \& Riva, G. (2017). Factors affecting patients' online health information-seeking behaviours: The role of the Patient Health Engagement (PHE) Model. Patient Education and Counseling, 100 (10), 1918-1927.

Hall, M. A., Zheng, B., Dugan, E., Camacho, F., Kidd, K. E., Mishra, A., \& Balkrishnan, R. (2002). Measuring Patients' Trust in their Primary Care Providers. Medical Care Research and Review, 59 (3), 293-318.

Hay, R. D., Davies, A. R., \& Ware, J. E. (1987). MOS Memorandum: Scoring the Medical Outcomes Study Patient Satisfaction Questionnaire: PSQ-III

Health Consumer Powerhouse. (2008). Euro Health Consumer Index 2008. Health Consumer Powerhouse AB.

Health Consumer Powerhouse. (2016). Euro Health Consumer Index 2008. Health Consumer Powerhouse AB.

HLS-EU Consortium (2012). Comparative Report of Health Literacy in Eight EU Member States. The European Health Literacy Survey HLS-EU (First revisesed and extended version, 2013), Online publication: http://www.health-literacy.eu

Jordan, J. E., Buchbinder, R., \& Osborne, R. H. (2010). Conceptualising health literacy from the patient perspective. Patient Education and Counseling, 79 (1), 36-42. 
Jordan, J. E., Buchbinder, R., Briggs, A. M., Elsworth, G. R., Busija, L., Batterham, R., \& Osborne, R. H. (2013). The Health Literacy Management Scale (HeLMS): A measure of an individual's capacity to seek, understand and use health information within the healthcare setting. Patient Education and Counseling, 91 (2), 228-235.

Kaphingst, K. A., Weaver, N. L., Wray, R. J., Brown, M. L. R., Buskirk, T., \& Kreuter, M. W. (2014). Effects of patient health literacy, patient engagement and a system-level health literacy attribute on patient-reported outcomes: a representative statewide survey. BMC Health Service Research, 14: 475.doi: 10.1186/1472-6963-14-475

Komenaka, I. K., Nodora, J. N., Machado, L., Hsu, C. H., Klemens, A. E., Martinez, M. E., Bouton, M. E., Wilhelmson, K. L., \& Weiss, B. D. (2014). Health literacy assessment and patient satisfaction in surgical practice. Surgery, 155 (3), 374-83.

Laidsaar - Powell, R. C., Bu, S., \& McCaferry, K. J. (2014). Partnering with and Involving Patients. In Martin, L. R. \& DiMatteo, M. R. (Eds.) The Oxford Handbook of Health Communication, Behavior Change, and Treatment Adherence (pp. 84-108). Oxford, New York: Oxford University Press.

MacLeod, S., Musich, S., Gulyas, S., Cheng, Y., Tkatch, R., Cempellin, D., Bhattarai, G. R., Hawkins, K., \&Yeh, C. S. (2017).The impact of inadequate health literacy on patient satisfaction, healthcare utilization, and expenditures among older adults. Geriatric Nursing, 38 (4), 334-341.

McCray, A. T. (2005). Promoting Health Literacy. Journal of the American Medical Informatics Association, 12 (2), 152-163.

Naidu, A. (2009). Factors affecting patient satisfaction and healthcare quality. International Journal of Health Care Quality Assurance, 22 (4), 366-381.

OECD (2017). OECD Health Policy Overview. Health Policy in Latvia. March 2017. Retrieved from http://www.oecd.org/els/health-systems/Health-Policy-in-Latvia-March-2017.pdf

Priporas, C. V., Laspa, C., \& Kamenidou, I. (2008). Patient satisfaction measurement for inhospital services: A pilot study in Greece. Journal of Medical Marketing, 8 (4), 325-340.

Rasnača, L., Vībane, K., \& N,ikišins, J. (2017). How proficiently do we take care of our health? How to become more skilful? In Holma, B. (Ed.) Latvia. Human Development Report 2015/2016. Mastery of Life and Information Literacy (pp. 16-26). Riga: Advanced Social and Political Research Institute of the University of Latvia. Retrieved from https://www.szf.lu.lv/fileadmin/user_upload/szf_faili/TAP-ENG-MOL_IL-2017.pdf

Shea, J. A., Guerra, C. E., Ravenell, K. L., McDonald, J.V., Henry, C. A. N., \& Asch, D. A. (2007). Health literacy weakly but consistently predicts primary care patient dissatisfaction. International Journal for Quality in Health Care, 19 (1), 45-49.

Sørensen, K., Van den Broucke, S., Fullam, J., Doyle, G., Pelikan, J., Slonska, Z., \& Brand, H. (2012). Health literacy and public health: A systematic review and integration of definitions and models, BMC Public Health, 12 (80).

The Standing Committee of European doctors. Doctors `and older patients `health literacy of functional decline and frailty. Results from Latvia and Romania. EU Policy Recommendations, Executive Summary and Full Study Results. https://ec.europa.eu/ eip/ageing/library/doctors-and-older-patients-health-literacy-functional-decline-andfrailty-results-latvia-0_en

Verkissen, M. N., Ezendam, N. P. M., Fransen, M. P., Essink-Bot, M., Aarts, M. J., Nicolaije, K. A. H., Vos, M. C., \&Husson, O. (2014). The role of health literacy in perceived information provision and satisfaction among women with ovarian tumors: A study from 
SOCIETY. INTEGRATION. EDUCATION

Proceedings of the International Scientific Conference. Volume VII, May $25^{\text {th }}-26^{\text {th }}$, 2018. 240-250

the population-based PROFILES registry. Patient Education and Counseling, 95 (3), 421-428.

Veselības ministrija (2017). Konceptuālais ziṇojums "Par veselības aprūpes sistēmas reformu”, pieejams: http://www.vm.gov.lv/lv/aktualitates/par_veselibas_aprupes_sistemas_ reformu/

Von Wagner, C., Steptoe, A., Wolf, W. S., \& Wardle, J. (2009). Health Literacy and Health Actions: A review and Framework from Health Psychology. Health Education and Behaviour, 36 (5), 860 - 877.

Ware, J. E., Snyder, M. K., \& Wright, W. R. (1976). Development and Validation of Scales to Measure Patient Satisfaction with Medical Care Services. 